\title{
ENTRE LITERATURA E DEMOCRACIA, UMA DEMANDA: POR UMA LITERATURA DEMOCRÁTICA
}

BETWEEN LITERATURE AND DEMOCRACY, A REQUEST: FOR A DEMOCRATIC LITERATURE

Taís Freire de Andrade Clark* Rafael Guimarães Tavares Silva**

RESUMO: Atendendo à demanda da revista Em Tese sobre as relaoees (im)possiveis entre literatura e democracia, propomos diferentes reflexões a partir de perspectivas teóricas advindas dos campos da Literatura, do Direito, do Urbanismo e da Filosofia, pautadas pelo direcionamento dos Estudos Culturais. A fim de reunirmos criativamente essa diversidade, decidimos abordar a questão de maneira plural, escrevendo a quatro mãos. Dentre as referências escolhidas, contamos com autores clássicos (Safo, Sólon e Tirteu), poetas contemporâneos (Ana C. César, Rafaela B. e Siscar), filósofos contemporâneos (Adorno, Arendt, Derrida, Horkheimer, Lefebvre e Rancière), criminólogos, sociólogos e urbanistas (Anyar de Castro, Harvey, Maricato e Vainer). Nosso objetivo é problematizar as ideias em torno de democracia literatura, de modo a criticá-las e, ao mesmo tempo, reconhecer suas potencialidades para o momento de crise que vivemos.

PALAVRAS-CHAVE: Democracia; Literatura; Filosofia; Espaço; Crise.

\author{
* tataclark@gmail.com \\ Mestranda em Arquitetura pela UFMG \\ *gtsilva.rafa@gmail.com \\ Mestrando em Letras pela UFMG.
}

ABSTRACT: Answering the call for papers of the journal Em Tese about the (im)possible relations between literature and democracy, we offer different reflections from theoretical perspectives risen from the fields of $L$ itera the Cultura Sudies. In order to assemble creatively this diversity, we the Cultural Studi, In order to assemble creatively this diversity, we hands. Among the referen (Sapp. A Rafa B and Siscar), contemporary philosophers (Adorno, Arendt, Derrida, Horkherer, Lobure and Rancière), criminologists, socioloDerida, Hond Siscar), conempory philowe gists and urba ists (Anyer de Castro, Hanvey, Maricato and Vainer). with a jective is to discuss the ideas around democracy and literature, whtialities for the moment of crisis we are living in

KEYWORDS: Democracy; Literature; Philosophy; Space; Crisis. 
1. Agradecemos ao parecerista da Em Tese, ignoto e arguto, por seus comentários bastante elucidativos das questões aqui abordadas.
Primeiramente - fora temer a inação de palavras esvaziadas no momento mais necessário - cabe àqueles que escrevem a crença de que escrever pode ser um gesto político. Ainda que nem sempre. ${ }^{1}$

Diante da crise do sistema representativo, tal como vivid de forma aguda pelo Brasil desde meados de 2013, parece-no urgente atender à demanda impossível contida na chamada da Em Tese v. 23, n. 1, quando seus editores, convocando autores a publicarem seus textos, escrevem:

We have a dream: um Dossiê que investigue a relação entre Literatura - em suas diversas manifestações, orais e escritas, líricas e épicas e dramáticas e ensaísticas - e Democracia seja quando ela existiu e/ou quando ela não pode existir, seja enquanto conceito e/ou enquanto forma social. (EM TESE, 2016).

Eu - assinando aqui Rafael Silva - pensei, a princípio, numa maneira de articular ideias que refletissem sobre as relações entre o espaço da literatura e o espaço da democracia, entre esses espaços e a utopia inerente a eles, levando em conta ainda os discursos sobre o advento de um tempo capaz de dar lugar para que tudo seja dito, todas as ideias defendidas, mesmo aquelas que se oponham à própria literatura e à própria democracia. Expondo tal demanda, bem como minhas primeiras ideias a esse respeito, à companheira
- assinando aqui Taís Clark -, fomos levados, por meio de m diálogo não isento de tensões, a considerar a situação de forma mais ampla e profunda: de que maneira, num país em que as taxas de analfabetismo são altas como no Brasil, haveria algum sentido em relacionar democracia e literatura (segundo seus entendimentos mais correntes, em sentido estrito)? ${ }^{2}$ Tal procedimento não dissimularia seu perverso fundamento numa exclusão de princípio, contaminando toda a discussão com uma inevitável impostura? Por outro lado aquilo que faz a especificidade do campo literário não deveria ser considerado para além de uma compreensão fechada nas condições de possibilidade para uma recepção efetiva (de uma perspectiva sociológica), também naquilo que envolve a produção da obra, sua apresentação enquanto tal, sua linguagem e até sua relação com a realidade? Ou ainda: para além das dimensões a serem privilegiadas numa análise como as esboçadas acima, até que ponto uma reflexão circunscrita ao âmbito de uma revista acadêmica de um curso de Letras poderia influir num debate que envolvesse, para além da literatura, também a democracia?

Colocados num estado de aporia diante desses questionamentos e de muitos outros que os entremearam no momento mesmo de nosso diálogo, pouco depois escutamos um eco frágil que nos veio de longe e tinha, contudo, uma capacidade de esclarecimento dificilmente negável: lá estávamos nós, um professor (estudante de literatura) e uma advogada
2. Exemplos do sentido estrito característico desses termos para o senso comum seriam aqueles oferecidos pelo dicionário Aurèllo (PERREIRA, 1999): "democracia. [Do gr. demokratia]. S.f. I. popular; demoratismo. [Cf. pulgor, democratismo. [Cr. regime político baseado nos princípios da soberania popular e da distribuição equitativa do poder, ou seja, regime de governo poder, ou seja, regime de governo pela liberdade do ato liberal,

pela divisão dos poderes e pelo controle da autoridade, i.e., dos poderes de decisão e de execução: democratismo. [...]." E: "literatura [Do lat. litteratura.] S.f. 1. Arte de compor ou escrever trabalhos artísticos em prosa ou verso. 2. O conjunto de trabalhos literários dum país ou duma época. [...]." 
(estudante de arquitetura), trazendo nosso diálogo ao banco de uma praça pública, em torno do qual nossos colegas, das mais diversas profissões, tomavam variados partidos na dis cussão, expondo-se em suas próprias argumentações, explicando-se, replicando-se e complicando-se, a fim de responder à impossível demanda que saía do editorial de uma revista acadêmica para se fazer presente naquela discussão, envolvendo agentes reais no mundo real. Nossa hesitação sobre as limitações inevitáveis a tal debate foi desfeita pela evidência do próprio debate.

A decisão estava tomada: escreveríamos um artigo a quatro mãos, expondo nossos respectivos argumentos em espaços, princípio, separados (a fim de demarcar, para cada discurso, seus traços e riscos específicos) e, ainda assim, unindo-nos no fim mesmo do debate. Com esse intuito, retomamos a estratégia de certos teóricos alemães confrontados com um período de crise sociopolítica, responsáveis por esboçar um retorno ao pensamento da antiguidade, com o intuito de criticar reflexivamente seu próprio presente: para isso, solicitamos ao debate certos poetas (tanto antigos quanto contemporâneos) no que se refere à dimensão política de sua atuação em performance. Na sequência, relacionamos o processo de urbanização intenso das cidades ao advento da democracia moderna, enfatizando as aparentes contradições do sistema capitalista e a importância de se insurgir contra elas, por meio da ampliação e ocupação de todo e qualquer espaço, inclusive do espaço da própria literatura. Na conclusão, refletindo sobre esses diferentes aspectos do debate, afirmamos um posicionamento de resistência incondicional, esperando apontar uma saída para uma aporia (im)possível.

$$
*
$$

A crise patente no engano a que chamamos de "democracia” arrasta-se há alguns anos no Brasil e, embora tenha atingido o ápice em meados de 2016, preocupa cada vez mais setores de nossa sociedade. Com relação à área de Letras, e principalmente do ensino de Literatura, publicações como Margens da democracia em 2015 (embora a partir de simpósios realizados em 2011) dão sinais evidentes de que o momento é percebido como crítico também entre profissionais da área - professores, escritores, estudantes e leitores.

Vários pensadores, de outros tempos e outros lugares, confrontados com um diagnóstico tão ou ainda mais catastrófico do que o nosso, refletiram sobre a situação tanto política quanto social e sugeriram uma série de ideias cuja retomada poderia se prestar como ponto de partida para minhas considerações. Eu poderia evocar, por exemplo, alguns autores alemães que - tendo sobrevivido aos horrores da Segunda Guerra Mundial - testemunharam a ruína de uma concepção de ser humano e de mundo e foram confrontados com o desafio de pensar em alternativas para a nova ordem mundial. A pertinência das considerações dessa época é ainda 
3. Retomo aqui a estratégia argumentativa de base empregada por esses autores como um ponto de partida para as minhas próprias reflexões. Arendt, Adorno e Horkheimer ensaiam, em obras desse periodo, um retorno aos da civilizac̃ão de, repensando-os, colocar questão ou retomar vários de seus pressupostos e estratégias. mais aguda entre autores judeus que, arrancados das próprias raízes culturais, foram obrigados a iniciar uma nova vida (sempre a mesma) em outro lugar e outro tempo. Falo de Hannah Arendt, Theodor Adorno e Max Horkheimer, embora muitos outros pudessem ser aqui mencionados. ${ }^{3}$

Nos escritos dessa época, da autoria de cada um deles, ressinto uma nostalgia (ainda que, paradoxalmente, sem vontade de retorno [nóstos]), como quando Adorno e Horkheimer, por exemplo, iniciam seu livro sobre a Dialética do Esclarecimento [Dialektik der Aufklärung] (1944) com uma leitura originalíssima da Odisseia e, mais precisamente, das aventuras de Odisseu, o herói do nóstos [retorno]. Algo análogo poderia ser dito sobre inúmeras passagens da Condição humana [The human condition] (1958), de Arendt, onde a autora fala dos séculos anteriores a Platão (ou seja, do período que precede o séc. IV) como um tempo de valorização da ação humana, em palavra e ato na esfera política, numa proporção que jamais seria vista de novo. Ainda que consciente das limitações da esfera política do período (da qual mulheres, estrangeiros e escravos estavam excluídos), Arendt parte da constatação de que o campo da ação pública foi preponderante nessa época e a contrapõe ao domínio que a esfera privada tem exercido cada vez com mais hegemonia no mundo moderno (em evidente detrimento da ideia de um mundo comum em que os seres humanos agiriam e seriam vistos agindo). Essas proposições ressoam com apelo especial para mim, na medida em que, interessado pelos estudos das línguas e culturas antigas, poderia sugerir um caminho análogo ao dos autores citados: partir da releitura de certos marcos do passado a fim de tentar guiar um pouco de nossa caminhada pelos velhos (e sempre novos) caminhos do presente.

O que me preocupa aqui é não apenas a democracia, mas sim sua relação com a literatura, de modo que, considerando a experiência dos gregos no campo da ação pública, eu seria levado a começar da relação existente para eles entre a política e a poesia a fim de refletir, em diferença, as possibilidades abertas para nós. Ou seja, num primeiro momento, extrapolarei as noções historicamente marcadas de democracia e literatura valendo-me das ideias mais amplas de politica e poesia. As diferenças subjacentes a essa analogia (democracia-literatura no Brasil contemporâneo, por um lado, e política-poesia na Grécia antiga, por outro) são grandes demais para que se tente esmiuçá-las aqui, mas o insight de Arendt, no que diz respeito à preponderância do campo da ação pública para os gregos antigos e o domínio da esfera privada para as sociedades contemporâneas, pode ser o fiel da balança em minha leitura crítica.

Que se considere a obra de um poeta como Calino de Éfeso (de meados do séc. VII a.C.), cujos versos iniciais do fr. $1 \mathrm{~W}$. (v. 1-4) anunciam o seguinte: 
4. Tradução minha. No original:
'mékhris téo katákeisthe? kót' "mélkimon héxete thymón, / ô néoi? alkimon héxete thymón,/ ô neooi? hôde líên methiéntes? en eirénēi dè dokeîte/ hêsthai, atàr pólemos gaîan hápasan ékhei?".

5. Para detalhes sobre isso, cf. IRWIN Solon and Early Greek Poetry: The Politics of Exhortation, p. 17-62. Em português, algumas dessas informaçôes foram retomadas por Brunhara (Elegia grega arcaica, ocasião de performance e tradição épica: O caso de Tirteu, p. 13-33).

6. Tradução minha. No original: "kaí tis apothnếiskōn hıstat' akontisátō."
Até quando inertes jazeis? Quando tereis ânimo audaz, ó jovens? E não vos envergonhais dos vizinhos, assim estando, assaz relaxados? Em paz então julgais estar sentados, mas a guerra toma a terra toda [...]. ${ }^{4}$

O poeta, escrevendo dísticos elegíacos e apresentando-os oralmente numa ocasião de performance pública, ${ }^{5}$ faz um apelo diretamente a seu auditório, por meio de uma significativa segunda pessoa do plural, cuja intensidade se torna ainda mais pungente devido ao tom de um discurso que, por meio da denúncia escancarada, desperta o senso de vergonha em seus ouvintes. As referências diretas a uma vida de relaxamento (como indicam os verbos katakeimai [estar reclinado], methiémi [relaxar] e hêmai [estar sentado]) chamam atenção para detalhes do momento atual da performance, destacan do-os a fim de ressaltar a incompatibilidade entre a atitude comentada negativamente e a realidade da situação desvelada Não é à toa que esse gênero poético é descrito como exortativo marcial: em seus versos há um verdadeiro apelo à tomada de armas por parte daqueles que compõem o público.

Aqui seria possível evocar versos de fato marciais, como na sequência do mesmo poema de Calino (fr. 1 W., v.5: "e que cada um, morrendo, lance o dardo pela última vez" $)^{6}$ ou em certas passagens de Tirteu (como, por exemplo, no fr. 12 W., v.10-12: "pois o homem não se torna bom na guerra/ se não ousar contemplar a matança sangrenta/ e se lançar aos inimigos, perto postando-se."). ${ }^{7}$ Mas para que minhas palavras não sejam interpretadas como algum tipo de apologia a soluções violentas para a crise que nos desafia, prefiro recorrer a evocações cujo apelo público seja menos a pulsões de morte e mais a pulsões de vida. O campo da ação pública não é menos preponderante na poesia desta grande poeta que é Safo, apesar de nossa educação romântica teimar em escutar nela os ecos de uma subjetiva "lírica" quase contemporânea, e os versos iniciais do fr. 16 Voigt são emblemáticos daquilo que é possível traçar entre a poesia (literatura) e a política (democracia), a partir de considerações sobre a antiguidade:

Uns, uma tropa de cavaleiros; outros, uma de soldados; outros, uma de navios, dizem sobre a terra negra

ser o que há de mais belo: mas eu, aquilo que se ama. ${ }^{9}$

Pode parecer estranho que, dentre toda a produção poética arcaica, eu escolha destacar justamente esses quatro versos de Safo, uma vez que outras opções poderiam demonstrar um engajamento público do poeta (e de seus ouvintes) muito mais evidente, como em inúmeros poemas de Sólon, que também foi um legislador ateniense, o que facilitaria um comentário desejoso de indicar certa relação de conteúdo entre poesia e política. Entretanto, acredito que Safo evidencie um
7. Tradução minha. No original: "ou gàr anè̀r agathòs gígnetai en polémōi,/ ei mè̀ tetlaíe mèn horô phónon haimatóenta/ kaì déíō orégoit' engıthen histámenos."

8. Para uma crítica dessa tendência, cf. RAGUSA. Lira Grega: Antologia de poesia arcaica, p. 11-35,

9. Tradução minha. No original: “Oi mèn ippếōn stróton, oi dè pésdōn oi dè náón phaîs' epì gân mélainan émmenai kálliston, égō dè kên' ót-/ tō tis ératai."
EM TESE
BELO HORIZONTE
v. 23
N. 1
JAN-ABR. 2017
CLARK; SILVA. Entre literatura e democracia, uma demanda: Por uma [...]
P. $67-84$ 
10. Valho-me aqui das considerações de Adorno sobre poesia, em ("Aufzeichnungen zu Kafka") seu texto sobre a parataxe de Hölderlin ("Parataxis. Zur späten Lyrik Hölderlins"), nos quais a noção de um teor de verdade [Wahrheitsgehalt] emerge da tensão entre o conteúdo material de um poema $[/ n h a l t]$ e seu teor espiritual [Gehalt].

11. Esse arranjo estrófico consiste em dois versos hendecassílabos $(-v-x$ -v-) e um terceiro que começa da mesma forma, mas continua com outras cinco sílabas adicionais (-v). Esse último é dado como um quarto verso estrofico, tanto em ediçoes antigas quanto modernas, sendo chamado adônico.

12. Para breves considerações sobre o contexto de performance em Safo, cf. RAGUSA. Lira Grega: Antologia de poesia arcaica, p. 95-100. A mesma estudiosa aprofunda suas pesquisas sobre a poesia sáfica em outros estudos acadêmicos. dos principais elementos dessa relação na própria forma de seu poema - ainda que, ao mesmo tempo, o tematize e promova um diálogo infinito entre o que se diz e o como se diz. ${ }^{10}$

Sua clássica estrofe sáfica, ${ }^{11}$ com os três primeiros versos compostos segundo um mesmo arranjo métrico bem balanceado e homogêneo, traz uma representação formal do aparente consenso que faria parte de algo da ordem do conteúdo, qual seja, a consideração relativamente consensual sobre aquilo que há de mais belo (uma tropa [stróton], seja ela de cavaleiros, soldados ou navios), numa expressão de matriz homérica na qual se lê a predominância masculina na sociedade helênica. Porém, o final do terceiro hendecassílabo e, sobretudo, o pequeno verso adônico ao fim introduzem a nota dissonante naquele arranjo totalitário masculino, inocula a diferença no cerne do que se pretenderia uma identidade a si e, dessa forma, inaugura a possibilidade de manifestação da alteridade que é característica fundamental (pelo menos enquanto potência) de toda comunidade política de fato. Vale notar que esse desvio, pequeno, sem dúvida, e advindo dos menores elementos contidos nessa grande estrofe, dá a ver o que há de mais ínfimo da perspectiva pública (o égō [eu]) no palco das manifestações majoritárias ["Oi men... oi de... o de..."] e desarticula a totalização do sistema que se pretenderia equilibrado e plenamente satisfeito consigo mesmo. Safo canta isso também numa performance pública ${ }^{12}$ e instaura um espaço de encontro dos corpos e dos pensamentos, revelando em sua poesia aquilo que me parece ser não apenas o seu próprio "teor de verdade" [Wahrheitsgehalt] mas também o "teor de verdade" da política. ${ }^{13}$

Aqui eu poderia partir dessas sugestões, ainda que bastante incipientes, e, fazendo do passado uma espécie de baliza para se compreender o presente, empregar uma analogia básica a fim de indicar de que modo a literatura e a democracia contemporâneas compartilham também um mesmo teor de verdade. Essa estratégia de retorno "interessado" ao passado foi empregada de forma bem sucedida por autores contemporâneos, tanto estudiosos da antiguidade quanto debatedores da modernidade, ${ }^{14}$ em vários campos das Humanidades, e o mesmo poderia ser feito a partir dos Estudos Literários. Na mesma linha do que foi afirmado sobre os versos de Safo, ou ainda, numa continuidade em diferença com ela, seria possível ler o seguinte poema, intitulado "Depois do amor" e publicado pela primeira vez em meados da década de 1990:

se um dia morrer o amor que nos une

se por descaso ou descuido eu estiver

enganado e o lóbulo da orelha esquecido

perder-se no espelho da sala ao lado escute

agora o que lhe digo esta voz que lhe diria

que a prefiro e para dizê-lo você será preciso ${ }^{15}$
13. Para a noção de Wahrheitsgehalt, remeto aqui mais uma vez aos escritos de Adorno sobre estética e poética, como suas anotações sobre Kafka ("Aufzeichnungen zu Kafka") ou seu texto sobre a parataxe de Hölderlin ("Parataxis. Zur späten Lyrik Hölderlins") Especialmente importante para o que se encontra em jogo na presente discussão, de ensaio como forma" e, de uma perspectiva conteudín " sobre lírica e sociedade" " A noção de um "teor de verdade" da política é um deslocamento para o campo da política a partir do que Adorno sugere para o campo da estética.

14. Exemplos possíveis seriam, além dos autores alemães já citados, Pierre Hadot (Qu'est-ce que la philosophie antique?), na filosofia, e José Antonio Dabdab Trabulsi ("A democracia ateniense e nós"),
na história.

15. SISCAR. Metade da arte, p. 113
EM TESE
BELO HORIZONTE
v. 23
N. 1
JAN.-ABR. 2017
CLARK; SILVA. Entre literatura e democracia, uma demanda: Por uma [...]
P. $67-84$ 
16. Aqui seria necessário ainda incluir a alteridade daquele que é falado, ou seja, daquele que parece não ter espaço diretamente no díalogo, posto que nem ocupa o lugar de, mas o de objeto do discurso. Concentrando a discussão no ponto, seria possível considerar a realidade social da relação que tem sido aqui proposta, entre literatura sido aqui proposta, entre literatu além dos limites inerentes a essa abordagem. Contudo, uma vez que essa dimensão parece ausente dos poemas aqui lidos, desejo voltar a ela no fim da discussão, quando algo sobre um além da relação entre literatura e democracia deve ser apontado.

17. Vale notar que o espaço instaurado pelo poema de Siscar, ao contrário do de Safo, é antes da ordem da intimidade do que da publicidade, como as mençoes ao "espelho da sala ao lado" e ao "lóbulo da orelha" bem o indicam. Isso tem relação com aquilo que Arendt trabalha em seu livro (a preponderância da esfera pública na antiguidade, enquanto modernidade privilegia a esfera privada da vida humana).
Para além da coincidência temática óbvia nos dois poemas, uma vez que o amor [érōs] se revela a condição de possibilidade para o estabelecimento de uma união real - de ordem afetiva (e estética), mas também "comunal" -, desejo destacar as possíveis implicações políticas subjacentes a ambos. Assim como Safo introduz a diferença no cerne do que se pretenderia uma identidade a si (qual seja, a voz totalitária da maioria), Siscar afirma que toda relação interpessoal, da qual o amor seria em minha leitura apenas a metonímia paradigmática, encontra fundamento na necessidade do outro. Ainda que essa relação venha a se revelar um fiasco no fim das contas, toda manifestação efetiva de identidade funda-se no reconhecimento de que a alteridade é algo preciso e de que só é possível viver as próprias possibilidades quando se está aberto a ela (e a dizê-la ao pé do ouvido). Nesse sentido, o poema de Siscar apresenta em sua forma moderna (a ausência de pontuação, de letras maiúsculas e de outros recursos tipográficos) uma aparente igualdade de partida entre o "eu" e o "outro", condição básica para que a diferença possa intermediar as relações entre a identidade de quem fala e alteridade daquele a quem se dirige. ${ }^{16}$ Não acredito que essa dimensão formal tencione o conteúdo tanto quanto faz o poema de Safo, mas o espaço estabelecido por "Depois do amor" indica em seu teor de verdade algo fundamental para a relação entre literatura e democracia contemporaneamente. ${ }^{17}$
Seria possível considerar outros exemplos literários contemporâneos para se pensar certa desconfiança com relação ao público, bem como seu consequente retraimento à esfera do privado, em poemas do próprio Siscar ${ }^{18}$ e de outros, mas abro mão dessa possibilidade para retomar algo que subjaz à argumentação de Arendt (e que é a base mais sólida de toda a argumentação aqui desenvolvida). Procedendo à diferença entre labor [trabalho] (ligado à satisfação das necessidades humanas vitais), work [obra] (designado para o aperfeiçoamento do instrumentário para a existência humana) e action [ação] (encarregado de liderar a condução da existência humana), a filósofa considera que o momento crítico vivido pela modernidade está relacionado a um descrédito da ação [action] e a uma supervalorização da obra [work] (ainda que consumida e compreendida como se fosse fruto de trabalho [labor]). O livro de Arendt não se pretende um manual de resolução da crise moderna, mas algo que ela afirma sobre a obra de arte, e mais especificamente sobre a poesia, parece indicar uma das vias possíveis para que a obra [work] possa mais uma vez se converter em ação [action].

A poesia, cujo material é a linguagem, talvez seja a mais humana e a menos mundana das artes, aquela cujo produto final permanece mais próximo do pensamento que o inspirou. A durabilidade de um poema é produzida por meio da condensação, de modo que é como se a linguagem falada com extrema
18. Cf., por exemplo, "Tudo é comum" (SISCAR. Metade da arte, p. 32) e (Docên 
19. ARENDT. A Condição Humana, p. 211.

20. De uma perspectiva social, basta mencionar: o trabalho de poetas como Ricardo Aleixo, e Sérgio Vaz; a popularidade de performances de rap ou de duelos de $M C^{\prime}$ 's; a retomada de saraus literários públicos (como o sarau ViraLata em Belo Horizonte). Da perspectiva do establishment, o Prêmio Nobel de Literatura conferido a Bob Dylan. De uma perspectiva acadêmica, os trabalhos de um Paul Zumthor sobre oralidade e performance poética ou de um Jean-Luc Nancy sobre a importância do corpo para uma teoria contemporânea mais consciente de si. densidade e concentração fosse poética por si mesma. [...] De todas as coisas do pensamento, a poesia é a mais próxima deste último, e dentre as obras de arte a que menos é uma coisa é um poema. ${ }^{19}$

Ainda que a própria Arendt considere todo poema, ao fim e ao cabo, dotado de uma exterioridade material responsável por coisificá-lo e impossibilitar que o poeta, enquanto tal, seja dotado de ação [action], eu gostaria de concluir essas breves considerações extrapolando os limites do que ela sugere. $\mathrm{Ou}$ seja, pretendo ir além dos limites implicados pela continuação do argumento acima citado de Arendt. Se compreendermos a poesia enquanto performance (e inúmeras manifestações culturais recentes têm demonstrado que isso é a cada dia mais inevitável), ${ }^{20}$ as ideias de uma palavra que age efetivamente e de uma ação que fala por si mesma estarão ligadas de forma profunda com a própria atividade poética (que passa, portanto, a implicar uma atitude poética). Conforme um estudioso recente dessa nova concepção de poesia:

Com efeito, nas formas poéticas transmitidas pela voz (ainda que elas tenham sido previamente compostas por escrito), autonomia relativa do texto, em relação à obra, diminui muito: podemos supor que, no extremo, o efeito textual desapareceria e que todo o lugar da obra se investiria dos elementos performanciais, não textuais, como a pessoa e o jogo do intérprete, o auditório, as circunstâncias, o ambiente cultural e, em profundidade, as relações inter-subjetivas, as relações entre a representação e o vivido. $^{21}$

Levando isso em conta, peço ao leitor que imagine o que são as performances poéticas em saraus públicos, duelos de MC's e outras ocasiões em que grandes diversidades de pessoas se encontram para manifestações públicas. A literatura - entendida num sentido muito mais amplo do que sua etimologia latina, relacionada à letra [littera], permitiria supor - está muito menos afastada da política do que seríamos levados a considerar num primeiro momento. Muito antes pelo contrário, lembrando o que foram as "intervenções poéticas" no período das ocupações de escolas secundaristas e universidades em todo o país durante o segundo semestre de 2016, em oposição aos desmandos implicados pela PEC 241/55 (cujos efeitos serão sentidos em breve no ensino e na saúde públicos), sou convencido de que uma relação fundamental entre a literatura e a democracia pode existir sim, a depender de como essas ideias forem trabalhadas e colocadas em prática.

Encerro aqui com a menção a um poema que escutei em novembro de 2016, durante uma performance acontecida na ocupação que teve lugar na Faculdade de Letras da UFMG. O poema de Ana Cristina Cesar, deslocado pela performer (cujo nome desconheço) para as circunstâncias específicas dessa
21. ZUMTHOR. Performance, recepção, leitura, p. 20-21. 
ocupação, apresentava a um só tempo: uma confrontação àqueles que - por muito ocupados - se recusavam a aparecer por ali; uma reflexão para aqueles que - ocupando - sentiam a ameaça que pesava sobre seus atos; uma sugestão para todos de que certa "desocupação" (entendida aqui no sentido da palavra grega skholé, como "tempo ocioso" normalmente voltado para o pensamento, donde a palavra "escola", do português, via latim), inevitavelmente ligada a uma "desocupação do corpo", deveria ter lugar para que ocupar fosse tornado de fato possível.

\section{ocupação}

o ato de escrever

ocupa metade da minha prosa e metade da minha vida outra metade.

\section{preocupação}

bilhete não respondido: que ameaças são essas?

\section{desocupação}

preciso sair da outra metade para ceder lugar ao iminente ato de foder. ${ }^{22}$
Preocupação. Talvez seja essa a palavra que melhor expresse o sentimento dos milhares de estudantes que ocuparam as escolas e universidades no fim de 2016. Preocupação com o ensino, preocupação com a política, preocupação com o futuro, preocupação com nossa democracia. Nesse cenário político, nada mais coerente, mais necessário e até mesmo óbvio, do que uma proposta de relacionar literatura e democracia. Mas é justamente da evidente necessidade de se discutir esse tema que surgem as dificuldades. Primeiramente, que democracia é essa que devo abordar? Um conceito vazio em uma doutrina jurídica? A nossa atual democracia brasileira? Podemos chamar o que temos hoje de democracia? E sobre a literatura: o que pode ser considerado literatura? Quem produz essa literatura? Para quem?

Essas perguntas constituem apenas o início de um questionamento mais profundo que tem surgido frequentemente nas universidades: qual é a relevância e o alcance dessa discussão feita dentro de uma revista acadêmica? E qual tem sido o papel da academia na construção política do nosso país? No início, confesso, estava um pouco cética em relação a essa proposta, mas a menina Rafaela B. ${ }^{23}$ de Diadema, me lembrou que esse é apenas o início, e que ocupar - escolas e espaços - importa.

Mas quem diria,

Uma menina ocupar uma escola
23. Rafaela B. é uma adolescente secundarista, ocupante de uma das escolas de Diadema, São Paulo, que teve o seu poema publicado na série de livros $A$ Poética dos Direitos Humanos, produzida pelo Coletivo Cultural Perifatividade, fundado em 2008 por poetas,

músicos, educadores e produtores culturais, oriundos do Fundão do Ipiranga, na região metropolitan de São Paulo. 
24. B. Sem título, p. 23.

25. HARVEY. Cidades Rebeldes.
Ela não tem medo de derrota

Ela tem fé pra chegar na vitória

Ela ri, ela chora

E aí garota, qual foi sua maior loucura

- Foi ocupar uma escola

Dias de luta, dias de glória

- Eis aqui o que não termina, Apenas se inicia... ${ }^{24}$

A experiência na praça Tahrir, no Cairo, mostrou ao mundo que a presença dos corpos nas ruas e praças realmente importa Desde então, ocupar o espaço público com corpos humanos se tornou uma forma eficaz de transformá-lo em uma arena política, em que as discussões e debates sobre diversos temas ocorrem de forma aberta e livre. ${ }^{25}$ Os movimentos que sucederam a Primavera Árabe, como o Occupy Wall Street, o Podemos na Espanha, as Manifestações de Junho de 2013 no Brasil, além de várias outras, dentre elas as recentes ocupações das escolas e universidades, possuem em comum a utilização da ocupação e apropriação do espaço público como demonstração da insatisfação com o sistema político e com as formas de governar.

Espalhando-se de uma cidade a outra, as táticas do Occupy Wall Street consistem em ocupar um espaço público central, como um parque ou uma praça, perto dos quais se concentram muitas das alavancas do poder e, ao colocar corpos humanos nesse lugar, transformar o espaço público em comuns políticos - um lugar para debates e discussões abertas sobre o que esse poder está fazendo e qual seria a melhor maneira de se opor a ele. Essa tática, notavelmente reativada nas nobres e atuais lutas que se travam na Praça Tahrir, no Cairo, espalhou-se pelo mundo inteiro (Puerta del Sol, em Madri, Praça Syntagma, em Atenas, e agora nas escadarias de São Paulo, em Londres e na própria Wall Street). Isso nos mostra que o poder coletivo dos corpos no espaço público ainda é o instrumento mais eficaz de oposição quando todos os outros meios de acesso encontram-se bloqueados. O que a Praça Tahrir mostrou ao mundo foi uma verdade óbvia: que os corpos nas ruas e praças, e não a tagarelice sentimental do Twitter ou do Facebook, é o que realmente importa. ${ }^{26}$

26. HARVEY. Cidades Rebeldes, p. 280-281.

Se vivemos em um regime intitulado democrático, em que a soberania é exercida pelo povo (conforme o art. $14 \mathrm{da}$ Constituição Federal), deveria parecer estranho que o simples ato de ocupar um espaço público seja considerado tão transgressor. Contudo, o direito de regulamentar o uso e a disposição do espaço público (e privado), assim como o direito à propriedade, à saúde, à educação, ao transporte, à moradia ou a qualquer direito social, parece pertencer a um grupo bem específico de pessoas, qual seja, àquelas que se assemelham muito às do Partido de Wall Street: 
27. VAINER. Os liberais também fazem planejamento urbano? Glosas ao "Plano Estratégico da Cidade do Rio de Janeiro", p. 116.

28. LEFEBVRE, Henry. O Direito à Cidade.

29. ADORNO. Palestra sobre lírica e sociedade, p. 69
Empresários e associações patronais ocupam sem mediações a cena pública. A notória ausência dos partidos políticos reforça um movimento geral de despolitização da questão urbana. É a democracia direta... da burguesia. É a relação direta e aberta entre poder público e empresários, organizando conjuntamente um plano. Em nome da participação, da cidadania, da parceria entre público e privado. ${ }^{27}$

Falar em democracia no século XXI, em que mais da metade das pessoas do mundo vivem em cidades, significa também falar sobre a questão urbana. Apesar da existência das cidades preceder o capitalismo, como lembra Lefebvre, é a partir da revolução industrial que se inicia o processo de urbanização que resultou nos grandes centros urbanos atuais. ${ }^{28} \mathrm{~A}$ grande aglomeração nas cidades gera demandas sociais em larga escala que muitas vezes os Estados, principalmente os capitalistas periféricos, marcados por uma distribuição de renda desigual, são incapazes de atender.

\section{Se, para Adorno,}

a idiossincrasia do espírito lírico contra a prepotência das coisas é uma forma de reação à coisificação do mundo, à dominação das mercadorias sobre os homens, que se propagou desde o início da Era Moderna e que, desde a Revolução Industrial, desdobrou-se em força dominante da vida, ${ }^{29}$ são as cidades que proporcionam os espaços para essa dominação. Conforme Maricato, considerando que o predomínio atual do capital financeiro internacional não se submete "ao ritmo ou às incertezas das instituições democráticas nacionais e engendra novas instituições que decidem mais do que os próprios parlamentos nacionais ou tribunais superiores", ${ }^{30}$ a necessidade de se pensar em políticas públicas com participação social, que faça frente ao novo imperialismo, surge como um desafio.

A literatura também não escapa dessa dominação. Inserida no mesmo sistema de produção, apesar de existirem exceções, é em larga medida determinada pelos presidentes das grandes editoras, pelos autores e acadêmicos consagrados, pelos donos das megalivrarias, cuja maioria pertence a uma parcela muito específica da população. O mesmo ocorre nas universidades, tanto os professores, quanto os alunos ( $\mathrm{fu}$ gindo um pouco da lógica apenas os funcionários), em sua grande maioria pertencem a uma classe social privilegiada (embora atualmente essa tendência talvez tenha diminuído um pouco). Ou seja, o sistema em que estamos inseridos, não apenas determina os atores das produções literária, acadêmica, artística e cultural, de um modo geral, como limita sua distribuição e alcance. ${ }^{31}$

Por isso a relutância inicial em escrever sobre democracia e literatura em uma revista acadêmica, pois, afinal, não
30. MARICATO Para entender a crise urbana, p. 68.
31. Para detalhes sobre o processo consolidado pelo estabelecimento de uma indústria cultural, em suas implicações acadêmicas literárias, cinematográficas, radiofonicas, entre outras, cf. ADORNO; HORKHEIMER. Dialética do esclarecimento: fragmentos filosóficos, p. 99-138.
EM TESE
BELO HORIZONTE
v. 23
N. 1
JAN.-ABR. 2017
CLARK; SILVA. Entre literatura e democracia, uma demanda: Por uma [... ]
P. $67-84$ 
32. HARVEY. Condição pós-moderna, p. 213.

33. VAZ. Entrevista, p. 327. estaríamos, essas mesmas pessoas privilegiadas, escrevendo para nós mesmas? Que democracia é essa em que nem todos têm acesso à literatura, ao debate acadêmico, aos veículos de comunicação? Esses são questionamentos importantes que devem ser sempre levados em consideração. Por outro lado como lembra David Harvey, "a capacidade de influenciar a produção de espaço é um importante meio de aumento do poder social". ${ }^{32}$ E esta revista acadêmica ainda é um espaço, ainda que não seja físico, e ocupá-lo importa.

Relembrar o papel que a literatura, juntamente com outras artes, exerceu durante os governos totalitários, no Brasil no mundo, basta para entender sua força e o poder contestador que ela pode trazer, mesmo quando o espaço para sua disseminação parece tão limitado. Em entrevista à Galeria de Arte BANERJ, o artista plástico Guilherme Vaz recorda que "por mais que a gente quisesse desenvolver uma linguagem lírica, ou puramente plástica, não dava. A repressão da época aguçava muito a sensibilidade da gente. [...] Tinha também a função de conscientizar as pessoas, por isso queríamos ocupar todos os espaços disponíveis". ${ }^{33}$

Por acreditar que a literatura, enquanto arte, quando possui esse caráter insurgente, consegue romper não só com as barreiras de um regime político totalitário, mas também transformar a realidade social, transpondo os obstáculos impostos pelo capital financeiro, resolvi embarcar nessa proposta. A realidade é que a produção literária contemporânea, mesmo que de forma muitas vezes ainda marginalizada, tem cada vez mais vindo das ruas, periferias e favelas (mesmo que os setores mais tradicionais da academia ainda não reconheçam esse fato). Talvez, a relevância de se discutir uma literatura mais democrática, dentro de uma revista acadêmica, seja exatamente provocar uma mudança gradual nesses setores.

Para uma compreensão mais aprofundada dessa literatura marginal (marginal aqui no sentido de estar à margem da grande mídia e do mercado editorial) é preciso que se tenha em mente o contexto de uma sociedade democrática [...], dentro dos moldes dos países capitalistas ocidentais, no ambiente das grandes cidades, na era da comunicação eletrônica e do domínio da mídia financiada pelas grandes empresas multinacionais. Em termos culturais, esse tipo de sociedade parece já reconhecer que existem divergências e não mais se concebe um padrão único de língua, tradições, lazer, religião e arte Esta sociedade não vive sob a égide de um consenso estético, mas sob o delicado regime da convivência entre as diferenças, em que tensões e rivalidades são normais. ${ }^{34}$

À semelhança do que ocorreu com as artes plásticas e com a música, a literatura também saiu de seu espaço tradicional de produção e tomou as ruas (praças e viadutos). De galerias de luxo a galpões industriais no modernismo e muros grafitados
34. LIMA. Guerrilha literária: $A$ voz dos excluídos na Internet, p. 201-202.
EM TESE
BELO HORIZONTE
v. 23
N. 1
JAN.-ABR. 2017
CLARK; SILVA. Entre literatura e democracia, uma demanda: Por uma [...]
p. $67-84$ 
35. Para um aprofundamento na visão do pixo e do graffiti como arte, ver a dissertação de Sandro José Cajé da Paixão: O meio é a paisagem: pixaçao e grafite como intervençốes em São Paulo.

36. Para uma reflexão sobre a história da música brasileira na década de 1950, ver artigo de Marcos Napolitano, professor do Departamento de História da FFLCH-USP, intitulado "A música brasileira na década de 1950". e pixados, ${ }^{35}$ a arte atualmente é produzida e recebida por outros setores da sociedade, além dos tradicionais. Da mesma forma, a música brasileira passou dos consagrados salões da bossa nova à aceitação e apropriação do samba do morro, ${ }^{36}$ como o ritmo brasileiro por excelência, até o reconhecimento do funk carioca, rap e hip hop. Agora a literatura presencia também essa transformação: do seleto público que participava dos privados salons literários aos abarrotados slams de resistência em espaços públicos, nota-se uma nítida abertura e diversidade nesse tipo de produção, que a academia tão raramente consegue ou quer abarcar.

A insurgência literária não se limita ao campo da poesia. Em uma intensidade crescente, desde a década de 1990, a denominada literatura de testemunho tem se fortalecido como forma de contestar a homogeneidade do discurso conservador, que se recusa a aceitar a pluralidade cultural.

A história do testemunho, antes da sua institucionalização, acompanha a do processo de erosão do discurso monológico do sujeito central europeu, branco, homem, heterossexual e letrado que ocorre a partir do final do século XVIII até o presente. Nessa linha de argumentação, o testemunho pode se vinculado à modernidade e à revolução industrial; isto é, ao processo desencadeado pela brutal alteração da vida cotidiana que foi a revolução industrial e que implicou em uma série de vivências, não só nos setores hegemônicos, mas também entre os setores marginalizados [da sociedade]. ${ }^{37}$

O aumento da produção, distribuição e acesso à literatura de testemunho ocorrido nas últimas décadas no Brasil poderia representar um movimento de abertura ao discurso "do outro". No entanto, Marco alerta que "insistir de forma militante no caráter democratizante dessa literatura de testemunho que traz para o mundo letrado o saber do subalterno" acaba levando a sociedade a crer que ações afirmativas (referentes à efetivação de direitos e garantias das minorias) conduzem necessariamente à ampliação da democracia moderna. ${ }^{38}$ Embora concorde em parte com Marco, que tem uma preocupação legítima com a normatização e cooptação de uma literatura insurgente (a qual, uma vez assimilada, perde o seu caráter transgressor), não consigo deixar de reconhecer que as poucas políticas públicas e mudanças na legislação que reconhecem direitos de minorias acabam viabilizando espaços ocupados de fato com sua produção intelectual e artística (da qual a literatura de testemunho constitui apenas uma parte). Isso não significa que a abertura desse espaço seja fácil, pelo contrário, consiste na conquista de anos de luta de vários movimentos sociais. Nesse sentido, reconhecer certos avanços significa reconhecer o trabalho das várias, e normalmente anônimas, pessoas que lutaram por eles.
37. ACHUGAR. Historias paralelas/ historias ejemplares: la Historia y la voz del otro, p. 54. Tradução minha. No original: «La historia del testimonio, previa a su la del proceso de erosión del discurso monológico de sujeto central europeo, blanco, masculino, heterosexuly letrado que se da desde fines

del siglo XVIII al presente. En

del siglo XVill al presente. En testimonio puede ser vinculado a la modernidad y a la revolución industrial; es decir, al proceso desatado durante la brutal alteración de la vida cotidiana que fue la revolución industrial y que implicó una serie de vivencias no solo en los sectores hegemónicos sino también entre los sectores marginados.».

38. MARCO. A literatura de testemunho e a violência de Estado, p. 49 
39. B. Sem título, p. 23

40. BRUM. Quanto valem 20 centavos?
Por outro lado, reconhecer avanços não implica em assumir que houve uma ampliação da democracia moderna e, nesse ponto, Marco faz um alerta válido: não podemos nos contentar com tão pouco. Para a literatura ser de fato democrática, produzida e lida por qualquer um, inúmeros avanços ainda são necessários. Cabe à academia decidir qual o papel pretende desempenhar nesse longo percurso, que, como escreveu Rafaela B., "apenas se inicia”. ${ }^{39}$

Retomando o grande marco representativo da crise atual, ao analisar as manifestações de 2013 em São Paulo, Eliane Brum enxergou o movimento como a ação mais significativa, "o ato mesmo de literalmente romper o imobilismo e se mover. ${ }^{40} \mathrm{~A}$ maior transgressão é andar - e por isso era também crucial andar na imensamente simbólica Avenida Paulista." Com tudo o que aconteceu depois disso, talvez hoje a ação mais significativa seja ocupar, física ou simbolicamente, não importa. Ocupar espaços existentes, criar e construir novos espaços, mais até do que movimentar, significa resistir.

O momento é crítico e resistir é preciso. Posicionar-se com relação à crise política atual não é apenas um direito de todos, mas um dever. Muitas vezes, sob uma pretensa neutralidade científica, a academia omite-se. Sabemos, contudo, que a situação atual toda omissão significa posicionar-se pela manutenção do status quo.
Refletir acerca das relações (im)possíveis entre literatura e democracia deveria também levar em conta as condições em que essas noções se desenvolvem na modernidade (a partir de meados do séc. XVIII). Aqui podemos retomar com proveito o que afirma Derrida:

A literatura, a invenção da literatura, é um fato europeu, pelo menos na sua origem. Não quero dizer eurocêntrico, mas sim que a literatura no sentido estrito é uma invenção, uma instituição europeia bastante jovem, bastante nova. Ela é contemporânea da própria ideia de democracia moderna. Basta dizer que a literatura é o direito de dizer tudo [le droit de tout dire]. É uma forma excepcional, é o direito à palavra pública em princípio sem censura. Naturalmente a literatura foi frequentemente censurada, como se sabe. $O$ conceito de literatura implica que se tenha o direito de dizer tudo. A literatura é então perfeitamente incompatível com um Estado não democrático. ${ }^{41}$

Esse posicionamento, contudo, descuida de uma diferença fundamental entre aquilo que surge como uma espécie de "ideal" da literatura, ancorado também num certo "ideal" da democracia, e deveria ser examinado de forma mais específica para cada contexto. Aqui poderíamos mencionar a problemática questão que vincula pertencer a uma determinada classe social à efetividade dos mais básicos direitos humanos
41. DERRIDA.. Premier entretien avec Jacques Derrida: «La solidarite nossa. No original: «La littérature l'invention de la littérature, c'est un fait européen, du moins à son origine. Je ne veux pas dire eurocentrique, je veux dire que la littérature au sens strict est une invention européenne assez jeune, assez nouvelle. Elle est contemporaine de l'idée même de démocratie moderne. Autant dire que la litterature, c'est le droit à la parole publique en principe sans censure. Naturellement la littérature a souvent été censurée, on le sait. Le concept de littérature implique qu'on ait le droit de tout dire. La littérature est donc parfaitement incompatible avec un État no démocratique."

EM TESE $\quad$ BELO HORIZONTE $\quad$ v. $23 \quad$ N. $1 \quad$ JAN.-ABR. $2017 \quad$ CLARK; SILVA. Entre literatura e democracia, uma demanda: Por uma [...] P. 67-84


(inclusive ao "direito de dizer tudo"). Nesse sentido, o posicionamento de Derrida acima exposto deveria ser modulado com o que pontua, sobre "nossas democracias", outro pensador do contexto francófono (e mais especificamente europeu):

Não vivemos em democracias. [...] Vivemos em Estados de direito oligárquicos, isto é, em Estados em que o poder da oligarquia é limitado pelo duplo reconhecimento da soberania popular e das liberdades individuais. Conhecemos bem as vantagens desse tipo de Estado, assim como seus limites. As eleições são livres. Em essência, asseguram a reprodução, com legendas intercambiáveis, do mesmo pessoal dominante, mas as urnas não são fraudadas e qualquer um pode se certificar disso sem arriscar a vida. A administração não é corrompida, exceto na questão dos contratos públicos, em que ela se confunde com os interesses dos partidos dominantes. As liberdades dos indivíduos são respeitadas, à custa de notáveis exceções em tudo que diga respeito à proteção das fronteiras e à segurança do território. A imprensa é livre: quem quiser fundar um jornal ou uma emissora de televisão com capacidade para atingir o conjunto da população, sem a ajuda das potências financeiras, terá sérias dificuldades, mas não será preso. Os direitos de associação, reunião e manifestação permitem a organização de uma vida democrática, isto é, uma vida política independente da esfera estatal.
Permitir é evidentemente uma palavra ambígua. Essas liberdades não são dádivas dos oligarcas. Foram conquistadas pela ação democrática e sua efetividade somente é mantida por meio dessa ação. Os "direitos do homem e do cidadão" são os direitos daqueles que os tornam reais. ${ }^{42}$

Se o que Rancière escreve tem pertinência com relação à democracia (especialmente no contexto europeu), o mesmo poderia ser pensado para a literatura. Se ela constitui o "direito de dizer tudo", é preciso se perguntar quem possui esse direito, quem é capaz de assegurá-lo e, no limite, se não seria antes um privilégio do que um direito.

O contexto dos países periféricos, no entanto, leva-nos a questionar o pretenso reconhecimento real da "soberania popular" e a pretensa garantia das "liberdades individuais". Apesar de tal reconhecimento talvez existir em alguma medida na França, vivemos em uma conjuntura bem distinta. Aqui, tal como afirma Lola Aniyar de Castro, ao tratar dos direitos humanos e suas garantias, é preciso levar em conta

primeiro, que a lei não tem como objeto transformar a sociedade, nem pode transformá-la. Segundo, que quando se fala de "proteger a sociedade", na verdade está-se falando de "proteger o sistema”. Portanto, em terceiro lugar, que os direitos humanos não foram definidos para serem protegidos. ${ }^{43}$
2. RANCIÈRE O ódio à democracia p. 94-5.
43. ANYAR DE CASTRO. Criminologia da Libertação, p. 124-125. 
De acordo com essa perspectiva, caberia refletir sobre o estatuto de uma democracia em que a efetividade dos direitos humanos ocorre para apenas uma restrita parcela da população, enquanto a maioria (os "outros") é obrigatoriamente excluída do acesso a esses direitos. No sistema em que estamos inseridos, a marginalização não é apenas uma consequência perversa da desigualdade social, mas uma realidade inerente ao próprio sistema, cuja reforma é estruturalmente impossível. O mesmo poderia ser considerado para a literatura, quando se leva em conta a realidade do mercado editorial, das grandes editoras livrarias, do cânone literário tradicional, em vista das pequenas editoras, dos escritores e das escritoras marginais.

Ainda que todas essas críticas possam e devam ser feitas com relação aos limites da pretensa liberdade política na democracia, ou da pretensa liberdade de expressão na literatura (entre muitos outros "direitos assegurados"), é preciso cuidado para que essas críticas não cumpram uma função contrária à intenção que as motiva. Criticando a "liberdade política" na democracia não se está propondo que ela deva ser abolida, mas sim que é necessário ampliá-la e torná-la efetiva na realidade. O mesmo sobre a "liberdade de expressão" na literatura: quem faz uma crítica dessas (normalmente) não está sugerindo a instauração de uma censura que limite ou coíba tal direito, mas sim que as condições factuais devam ser desenvolvidas para que a literatura possa se transformar de fato num instrumento democrático.
A posição delicada de quem critica certos aspectos de um determinado direito, apontando seus pontos cegos ou sua ineficácia na realidade, é o risco de ver sua crítica sendo interpretada como se fosse simplesmente um ataque à existência daquele direito. Tal foi o risco que Derrida correu ao criticar as implicações negativas que uma certa compreensão de "humano" (e ainda mais evidentemente de "homem") tiveram para o desenvolvimento da filosofia ocidental, sobretudo em sua elaboração a partir de uma série de dicotomias como "humano/ animal" ou "homem/ mulher". ${ }^{44}$ Da mesma forma, a leitura crítica que Rancière faz da ideia de democracia corre o risco de ser mal interpretada por alguém que a julgue apenas pelo título de seu livro: $O$ ódio à democracia. ${ }^{45}$ Finalmente, em relação a Lola Anyar de Castro, seu questionamento à legislação de forma alguma representa uma proposta de abolição dos direitos fundamentais, pelo contrário, almeja a consolidação de instrumentos que permitam maior proteção a eles. ${ }^{46}$

É preciso criticar sempre, mas o momento é de resistência.

\section{REFERÊNCIAS}

ACHUGAR, Hugo. Historias paralelas/historias ejemplares:

la Historia y la voz del otro, Revista de Crítica Literaria

Latinoamericana, Lima-Berkeley, n. 36, 1992, p. 51-73.

ADORNO, Theodor W. Aufzeichnungen zu Kafka. In: ADORNO, Theodor W. Prismen. Kulturkritik und Gesellschaft. Gesammelte Schriften. Frankfurt a.M: Suhrkamp, 1997a, p. 254-87.
44. Com relação a isso, Derrida mostra-se lúcido sobre a importância da elaboração dos "direitos humanos" ou da noção de "crime contra a humanidade", ainda que partindo de uma concepção bastante estreita do que é próprio do ser humano. Cf. DERRIDA. Premier entretien avec des vivants», p. 129-31.

45. O próprio autor mostra-se consciente desse risco e tenta precaver-se contra ele quando, no ódio à deu livro, " una sobre desse ódio é acua: "Ã vión dúvida. No entanto, não é ele o objeto deste livro, pelo simples fato de que não tenho nada em comum com aqueles que o proferem portanto, não tenho nada que discutir com eles." (RANCIËRE. $O$ ódio à democracia, p. 08).

46. A questão dos direitos humanos no contexto latino-americano é mais bem explorada por Lola Anyar Libertação, p. 115-32). 
ADORNO, Theodor W. O ensaio como forma. In: ADORNO, Theodor W. Notas de literatura I. Trad. Jorge M. B. de Almeida. São Paulo: Duas Cidades: Editora 34, 2012a [orig. 1974], p. 15-46.

ADORNO, Theodor W. Palestra sobre lírica e sociedade. In ADORNO, Theodor W. Notas de literatura I. Trad. Jorge M. B. de Almeida. São Paulo: Duas Cidades; Editora 34, 2012b [orig. 1974], p. 65-90.

ADORNO, Theodor W. Parataxis. Zur späten Lyrik Hölderlins. In: ADORNO, Theodor W. Noten zur Literatur III. Gesammelte Schriften. Frankfurt am Main: Suhrkamp, 1997b, p. 447-91.

ADORNO, Theodor W. HORKHEIMER, Max. Dialética do esclarecimento: fragmentos filosóficos. Trad. Guido Antonio de Almedia. Rio de Janeiro: Jorge Zahar Ed., 1985 [orig. 1944].

ANYAR DE CASTRO, Lola. Criminologia da Libertação. Rio de Janeiro: Revan/ICC, 2005.

ARENDT, Hannah. A Condição Humana. Trad. Roberto Raposo. 12. ed. rev. - Rio de Janeiro: Forense Universitária, 2014 [orig. 1958

B., Rafaela. Sem título. In: COLETIVO PERIFATIVIDADE. A poética dos Direitos Humanos: Perifatividade nas escolas, vol. III. São Paulo: Perifatividade, 2016, p. 23.

BRUM, Eliane. Quanto valem 20 centavos? Rio de Janeiro:

Época, 17 jun. 2013. Disponível em: <http://revistaepoca.globo. com/Sociedade/eliane-brum/noticia/2013/06/quanto-valem-20centavos.html >. Acesso em: 01 abr. 2017.
BRUNHARA, Rafael de Carvalho Matiello. Elegia grega arcaica ocasião de performance e tradição épica: $O$ caso de Tirteu.

Dissertação (Mestrado em Letras Clássicas) - Departamento de Letras Clássicas e Vernáculas da Faculdade de Filosofia, Letras e Ciências Humanas, Universidade de São Paulo, São Paulo. 2012.

CESAR, Ana Cristina. Poética. São Paulo: Companhia das Letras, 2013.

DABDAB TRABULSI, José Antonio. A democracia ateniense e nós. e-hum Revista Científica das áreas de História, Letras, Educação e Serviço Social do Centro Universitário de Belo 2016, p. 8-31. Disponível em: < http://revistas.unibh.br/index.php/ dchla/article/view/2144>. Acesso em: 22 mar. 2017.

DERRIDA, Jacques. Premier entretien avec Jacques Derrida: «La solidarité des vivants ». In: DERRIDA, Jacques; NASCIMENTO, Evando. La Solidarité des vivants et le pardon. Paris: Éditions Hermann, 2016, p. 121-40.

EM TESE. Notícias: Literatura e democracia. Em Tese, Belo Horizonte 16 dez. 2016. Disponível em: < http://www.periodicos.letras.ufmg.br/ index.php/emtese/announcement>. Acesso em: 22 mar. 2017.

FERREIRA, Aurélio Buarque de Holanda. Novo Aurélio Século XXI: o dicionário da língua portuguesa. 3. ed. totalmente revista e ampliada. Rio de Janeiro: Nova Fronteira, 1999.

HADOT, Pierre, Qu'est-ce que la philosophie antique? Paris Éditions Gallimard, 1995

HARVEY, David. Cidades Rebeldes. Trad. Jeferson Camargo. São Paulo: Martins Fontes, 2014 
HARVEY, David. Condição pós-moderna. Trad. Adail Ubirajara Sobral e Maria Stela Gonçalves. São Paulo: Edições Loyola, 1992

IRWIN, Elizabeth. Solon and Early Greek Poetry: The Politics of Exhortation. Cambridge: Cambridge University Press, 2005.

LEFEBVRE, Henry. O Direito à Cidade. Trad. Rubens Eduardo Frias. 5.ed. São Paulo: Centauro, 2008

LIMA, Luciano Rodrigues. Guerrilha literária: A voz dos excluídos na Internet. Légua \& meia: Revista de literatura e diversidade cultural, Feira de Santana, v. 3, nº 2, 2004, p. 201-208. Disponíve em: <http://www2.uefs.br/leguaemeia/2/2 201-208Guerrilha. pdf $>$. Acesso em: 20 mar. 2017

MARCO, Valeria de. A literatura de testemunho e a violência de Estado. Lua Nova, São Paulo, n. 62, 2004, p. 45-68. Disponível em <www.scielo.br/pdf//n/n62/a04n62.pdf>. Acesso em: 16 mar. 2017.

\section{MARICATO, Ermínia. Para entender a crise urbana. São Paulo:} Expressão Popular, 2015

NAPOLITANO, Marcos. A música brasileira na década de 1950 Revista USP, São Paulo, n. 87, set./nov. 2010, p. 56-73. Disponíve em: <http://www.revistas.usp.br/revusp/article/view/13830> Acesso em: 20 mar. 2017

PAIXÃO Sandro José Cajé da. O meio é a paisagem: pixação e grafite como intervenções em São Paulo. 2011. Dissertação (Mestrado em Interunidades em Estética e História da Arte) Universidade de São Paulo, São Paulo, 2011. Disponível em $<$ http://www.teses.usp.br/teses/disponiveis/93/93131/tde15062012-134631/pt-br.php>. Acesso em: 20 mar. 2017.
RAGUSA, Giuliana (Org. e trad.). Lira Grega: Antologia de poesia arcaica. São Paulo: Hedra, 2014

RANCIĖRE, Jacques. $\mathbf{O}$ ódio à democracia. Trad. Mariana Echalar. São Paulo: Boitempo, 2014

SISCAR, Marcos. Metade da arte. São Paulo: Rio de Janeiro: Cosac Naify; 7 Letras, 2003

\section{SISCAR, Marcos; NATALI, Marcos (Org.). Margens da}

democracia: A literatura e a questão da diferença. São Paulo Campinas: Editora da USP; Editora da Unicamp, 2015.

VAINER, Carlos. Os liberais também fazem planejamento urbano? Glosas ao "Plano Estratégico da Cidade do Rio de Janeiro". In: ARANTES, Otília; VAINER, Carlos; MARICATO, Ermínia. A Cidade do Pensamento Único: desmanchando consensos. Petrópolis: Vozes, 2000, p. 105-20

VAZ, Guilherme. Entrevista. In: GALERIA DE ARTE BANERJ. Ciclo de Exposições sobre Arte no Rio de Janeiro. Rio de Janeiro: Galeria de Arte BANERJ, 1986, p. 320-325.

WEST, Martin L. lambi et elegi Graeci ante Alexandrum cantati. 2. ed. aucta atque emendata. Oxford: Oxford University Press, 1992

ZUMTHOR, Paul. Performance, recepção, leitura. Trad. Jerusa Pires Ferreira e Suely Fenerich. São Paulo: Cosac Naify, 2014. 